\title{
In-house development of scheduling decision support systems: case study for scheduling semiconductor device test operations
}

\author{
T. FREED $\quad$ K. H. DOERR and T. CHANC
}

Most manufacturing processes can benefit from an automated scheduling system. However, the design of a fast, computerised scheduling system that achicves high-quality results and requires minimal resources is a difficult undertaking. Efficient scheduling of a semiconductor device test facility requires an information system that provides good schedules quickly. Semiconductor device testing is the last stage of the long semiconductor manufacturing process, and therefore is subjected to customer service pressures. The cost of an off-the-shelf computerised scheduling system may be prohibitive for many companies. In addition, many companies are taken aback by other characteristics of off-the-shelf scheduling systems, such as code confidentiality, maintenance costs, and failure rates. We draw upon the literature and our field case to discuss some of the trade-offs between in-house development and off-the-shell acquisition of software. We describe the in-house design and implementation of a scheduling decision : support system for one device test facility. Using the design and implementation process of this system as a case study, we discuss how one facility uses in-house design of systems in a strategic way, as a competitive capability.

Keywords: Scheduling; Semiconductor manufacturing; Decision support systems; Make-or-buy; Organisational learning

\section{Introduction}

Many manufacturing processes may bencfit from an automated scheduling system. However, the design of a fast, computerised scheduling system that achieves high-quality results and requires minimal resources is a difficult undertaking.

The cost of an 'off-the-shelf' computerised scheduling system may be prohibitive for many companies. In addition, in our experience many companies are taken aback by other characteristics of off-the-shelf scheduling systems, such as code confidentiality, maintenance costs, and failure rates. We will use the term 'off-theshelf throughout this article to refer to software that is purchased from a vendor, with the understanding that the user-interface, and to some limited extent 
the execution, of that sofware will need to be modified during implementation. While some would argue that a system needing such modification is not truly off-the-shelf, we would argue that for manufacturing scheduling systems, some customisation is always required.

Efficient scheduling of a semiconductor device test facility requires an information system that provides good schedules quickly. Semiconductor device testing is the last stage of the long semiconductor manufacturing process. and therefore is subjected to customer service pressures. We describe the design and implementation of a scheduling decision support system for a device test ficility. Using the design and implementation process of this system as a case study. we further explore the potential benefits of in-house design of scheduling systems for small to medium-size companies.

The design and development of the in-house system was completed in four months by a three-person team, all full-time company employees. The team consisted of two industrial engineers and a process expert (past production manager). System implementation was completed in three months. Upgrades and modilications requested by production management and workers continued to be performed by one of the industrial engineers, who devoted approximately one day a week to the task.

Shortly after implementation of the in-house system, on-time delivery (the main manufacturing performance measure for the test facility) increased from $70 \%$ to $90 \%$ on average. Lot lead-times decreased by approximately $30 \%$. While this wats not a controlled experiment, to our knowledge there were no other major changes in production or demand that would have explained this improvement. As detailed below, time and effort to create a daily schedule and to re-schedule the test facility were reduced significantly.

The system had approximately 40 uscrs, including both direct users and managers reviewing the schedule with various levels of education and process experlise. In order to accommodate the needs and computer skill levels of the various users, special efforts were made by the developers to design a 'transparent', user-friendly system. While no systematic data were gathered on user perceptions of transparency or case-of-use, existing relationships between the developers and users of the systcm facilitated open communications about usability issues: by the end of the implementation process, there were no outstanding issues or user requests related to usability.

In-house development and execution had significant impact on organisational learning. In particular, using the system contributed to the organisational understanding of capacity issues and scheduling tradeoffs. The reports generated by the system led to the identification of problem areas, and to focused process improvement efforts. The longer-term production planning process also benefitted from the more accurate capacity estimates provided by the system.

The organisation that owned our field sitc, Xilinx Inc., is a firm that has a culture which has supported in-house development of operations software, as a competitive technology. While other firms, especially before the 'tech bubble' burst, invested large sums in off-the-shelf planning and scheduling and supply chain optimisation software, Xilinx invested not only in the scheduling system reported in this paper, but in the development of an in-house solution for application integration (an
'information bus'), manufacturing execution system, planning system, and heavily 
customised a unique competitive solution for forceasting. Beyond the rhetoric of vision and goals, investments must be made to support operational capabilities a firm wishes to develop for strategic advantage (Stalk et al. 1992). Xilinx invests in technically qualified personnel who can understand both software development, and the manufacturing processes involved. Three of the Xilinx employees involved in the software projects just outlined held PhDs (two with degrees in Industrial Engincering from Berkeley, one with a degree in Information Systems from Stanford). While advanced technical degrees may be common in research and development of firms such as Xilinx (which is, after all, a technology company), in our experience it is less common to find advanced technical degrees in the planning and manufacturing organisations.

Semiconductor device testing is the last stage of the semiconductor manufacturing process. At the Xilinx test floor in San Jose, California, dozens of lots of semiconductor devices are processed daily. Due to the level of competitiveness in this industry, efficient and timely processing is crucial to the company's success. Before the system was implemented, the main test-floor performance measure, lot on-time delivery (fraction of lots completed by their due-date), was unacceptable- $75 \%$ on average. In addition, lot lead-times were prohibitively long.

Historically, lot'scheduling had been performed by the production manager. Due to the overwhelming volume of lot information and the level of uncertainty inherent to this manufacturing environment, the scheduling task typically consumed more than half of the production manager's time. The production manager was required to work seven days a week, since no one else was capable of developing a daily schedule.

Developing a better scheduling methodology for the test-floor was necessary. The main challenges of the new system were to increase average on-time delivery to $90 \%$ and to decrease average lot lead-time by at least $25 \%$. The system had to be user friendly to people with limited computer experience (e.g. test-lloor supervisors and workers), and provide solutions fast (within minutes), so that a new schedule could be easily created when conditions changed (e.g. machine breakdown).

After reviewing several commercial scheduling packages, a decision was made to develop the system in-house. A team of three full-time company employees (including the production manager/scheduler), designed and implemented the scheduling decision support system.

The method applied in this paper is that of a case study, in its typical role of theory building (Lee 1999). However, we will not build a grand theory broadly addressing the question of software outsourcing. Rather, we will present a unique case that raises theoretical questions about what has been, to our mind, the overwhelming recent trend toward outsourcing software solutions. The first and third authors of this paper helped conduct the reported revicw of commercial scheduling packages, and formed the core of the development team for the in-house solution. The second author worked for onc of the commercial scheduling vendors being evaluated. Thus, this paper is not written in the typical logical positivist frame of reference, but is rather written in an interpretivist frame, by actors involved in the event, who are candidly advocates of the solution that was obtained. As such, it is conducted in the spirit of action research (Lewin 1946) and appreciative inquiry. We belicve it has value for managers and researchers outside our organisations because it provides (we hopc) a vivid and thoughtful counter-example 
to the recent trend to outsource, that should be useful in future theory building or decision making.

In the following sections we describe the semiconductor device test process and the scheduling performance goals. We explain the decision to develop the system in-house and provide a technical description of the system. The benelits of the system are then summarised, including a testimonial of the Senior Director of Operations.

\section{Process characteristics}

The semiconductor device test sub-process receives high visibility since it is the last stage of the semiconductor manufacturing process. From the test facility devies are shipped to customers and distribution centers, or transferred to finished goods inventory. A typical test-floor includes several processing operations: burn-in, electrical testing, marking/branding, baking, programming, mechanical scanning. quality check and packaging, in this order (see figure 1).

The test-floor can be described as a flexible flow-shop, i.e. the secucnee of processing opcrations is fixed, each lot requires a unique subset of the operations (burn-in, marking, baking, and programming may or may not be required). and multiple machines may be eligible for each operation. Since these mathines may not be identical with respect to processing rates and/or output quality, there may be lot assignment preferences among the set of eligible machines for an operation (sec Leachman and Carmon (Freed) 1992 for further discussion on machine llexibility).

Yield and lead-time variability in previous stages of the manulacturing process (i.e., wafer fabrication and assembly-see figure 2) result in variable lot sizes and lot priorities at the test sub-process. Yield loss at the test and scan operations maly also be significant and affect lot size and processing time at downstream operations. Lot priorities range from low priority lots to 'hot' lots that may justify pre-emption of other lots.

Machine failures are common and unpredictable. Preventive maintenamec is significant, but cannot eliminate frequent breakdowns. Machines are more likcly to fail during a changeover from one type of lot to a significantly different one.

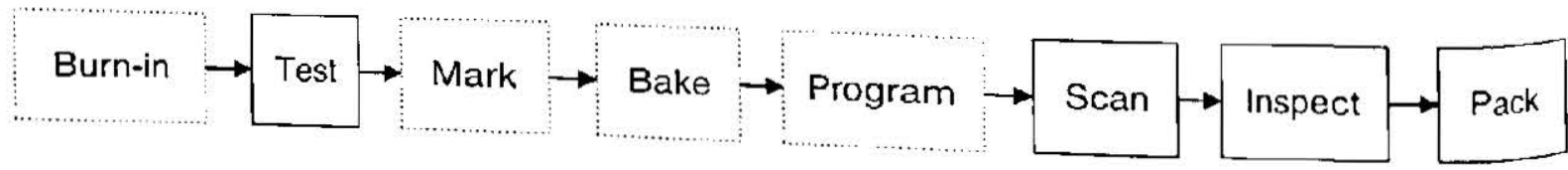

Figure 1. Test floor manufacturing process.



Days or weeks

Figure 2. Semiconductor manufacturing-sub-process lead-times. 
Changeover durations are significant (same order of magnitude as lot processing durations), variable and sequence-dependent. For further discussion of the complexity of scheduling semiconductor device test operations the reader is referred to Uzsoy et al. (1992a, 1994), to Carmon (Freed) (1995), and to Freed and Leachman (2001).

Test-floor workers have various skill levels and skill sets. Some workers can operate subsets of the machines, and others can operate all machines but subsets of product types. Labour cost is substantial (due to training time and cost, as well as skilled labour shortage), thus skilled labour capacity constrains throughput. A worker may be assigned to operate two or more machines, therefore lost capacity duc to machine interference is common.

\section{Performance goals}

A semiconductor company would typically hold a large buffer inventory (Dic Bank) between the wafer fabrication sub-process (front-end) and the assembly and test sub-process (back-end), in an attempt to absorb production fluctuations in the front-end and facilitate produce-to-order in the back-end (sce figure 2).

When transferred from Die Bank into the beginning of its assembly and test sub-process, each lot is assigned a due-date. By the due date the lot should complete the manufacturing process and either be shipped to its customer/distribution centre or transferred into finished goods inventory (FGI). The due date is determined based on the allowed assembly and test flow-time (also called lead-time or cycle-time) for the lot. It is common practice to set the due-dates such that $95 \%$ of the lots are expected to achieve the goal of on-time delivery. In an effort to continuously improve, allowed flow-times are decreased once the 95\% OTD goal has been achieved.

The test facility is typically concerned with three goals:

1. Maximising on-time delivery (OTD), measured as the fraction of lots shipped or transferred to FGI before midnight of their due-date (maximising OTD is practically equivalent to minimising the number of tardy lots).

2. Minimising cycle-time, measured as the number of days from the beginning of the assembly process to shipping or transfer to FGI.

3. Maximising tester utilisation, since the testers are the most capital-intensive machines and the process' typical bottleneck.

The OTD performance of make-to-order lots is important for customer satisfaction. Maximising OTD of make-to-stock lots is partially overlapping with minimising the mean and variance of the cycle-time, which, in turn can lead to increased sales and inventory reduction. The equipment utilisation performance measure is an indirect measure of facility throughput and manufacturing cost.

Due to dynamic changes in market conditions, customer requirements, corporate financial goals, and other business objectives conflicts among performance measures are common (e.g. OTD versus utilisation) and must be balanced. The scheduling system must be flexible enough to accommodate multiple, time-varying objectives. 


\section{Scheduling methods in the semiconductor industry}

Some semiconductor companies use scheduling modules that are part of their manufacturing execution system (MES). Other firms use commercial, stand-alone scheduling systems. Yet others use software written in-house; and as mentioned earlier, the authors have also seen firms where the production manager or other highly qualified personnel perform the scheduling task manually. For test scheduling solution techniques the reader is referred to the series of papers by Carmon (Ireed) (1995), Chen et al. (1995), Herrmann et al. (1995), Lee e't al. (1993), Uzsoy 't al. (1993), Ovacik and Uzsoy (1992, 1994a, 1994b, 1995, 1996), and to the papers by Uzsoy et al. (1991), Uzsoy et al. (1992b), Chen and Hsia (1997). Demirkol and Usoy (1997), Xiong and Zhou (1998) and Freed and Leachman (2001).

There are substantial differences in process characteristics among semiconductor manufacturers. For example, some companies test only at room temperature, while others must track temperatures and environmental conditions. Therefore. commercially available scheduling systems have generic functionality that is greater than the needs of any specific application. Generic systems also require significant customisation to each application. Due to the inherent complexity of the process, scheduling solutions are typically achieved using heuristic algorithms or simulation. Based on the software survey conducted as a part of this study (summarised below). and based on the experience of the second author (who was employed by a major scheduling software vendor at the time of this study), a typical scheduling system or module for a semiconductor company costs hundreds of thousands of dollars upfront, and a substantial additional cost for customisation. Over the life of at scheduling system maintenance costs are of similar order of magnitude. Most vendors would not release the code to their customers, so customisalion and maintenance must typically be contracted to the original system vendor. who thus has a potential conflict of interest in terms of developing robust, easy-to-maintain code.

\section{Make-or-buy decision}

The factors used to evaluate the make or buy decision at Xilinx are grouped into categories and shown in table 1 . The categories are explained in more delail below. and the evaluation of in-house versus off-the-shelf software is diseussed in terms of each factor.

Obviously, the factors listed in table 1 are amenable to a multi-criteria decision making (mcdm) tool such as the analytical hierarchy process (Sataty 1994). While such an approach was considered, in the end (as we will show) the choice was sufficiently clear that the use of an medm tool was deemed unnecessary. Had the options been more equally valued, or if the choice had to be made between similar off-the-shelf systems, an mcdm tool would have proved useful.

\section{Operational efficiency and effectiveness}

The test-floor manufacturing environment is complex, fast-changing, and subject to conflicting objectives. A recent survey of business process managers found those 
'Table, I. Factors affecting the make or buy decision.

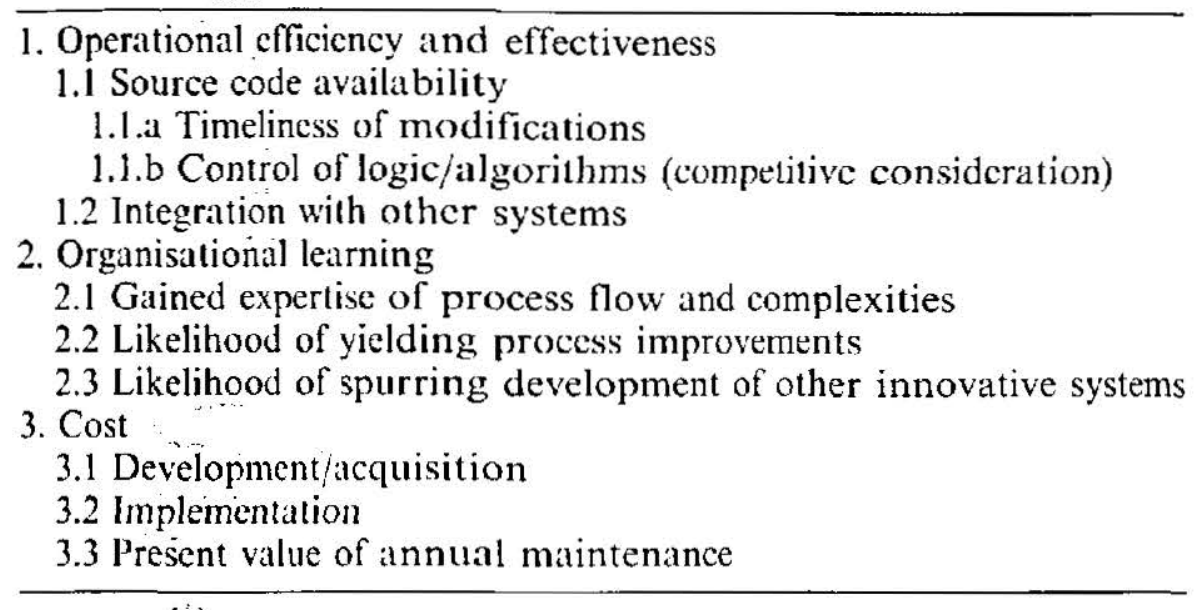

managers believe that in-house systems lead to superior process performance compared to off-the-shelf systems (Downing et al. 2003). In the case of scheduling systems, this may be because the level of customisation required of a generic scheduling system is very high if the system is to be accurate enough to provide reasonable solutions. In fact, the customisation effort in this case was estimated to be similar to designing a completely customised system, tailored to the Xilinx test-floor needs.

Most commercial scheduling systems provide solutions to the scheduling problem, and are not designed as decision support systems. In our experience, vendors are reluctant to release information about the algorithms used, and the quality of a scheduling solution provided by software may sometimes be inferior to that of a manual solution provided by the company's scheduling expert. Take, for cxample, a case of scheduling a particular customer order knowing that a previous order for this customer was delayed. The importance of on time delivery for this particular customer order may be higher than normal. However, special treatment of this particular order is impossible to incorporate in any of the solution algorithms we examined. Some of the software providers incorporate sophisticated user interfaces to facilitate after-the-fact modifications of solutions to allow users to account for such unmodelled considerations (Schneeweiss and Wetterauer 2005). But after-thefact modifications, however good the user interface, are not the same as building solutions in a flexible, interactive way. The second author remembers saying in a wondering tone at one meeting: 'You expect people to pay $\$ 400,000$ so that they can tell you what their schedule should be?'

There is a range of applications here, from simple closed-loop presentation of a canned solution: which cannot be modified, through dynamic algorithms that can account for changing situations within a limited modelling framework, to fully interactive support systems which provide recommendations, along with a transparent set of reasoning, and allow for modification and interaction as the schedule is being built (Godin 1978, McKay et al. 1988, Glassy 1991). While afterthe-fact modification is an improvement on the flexibility of batch scheduling, it is still short of fully interactive scheduling. Since the algorithms are not understood and cannot be improved by the users, it may be difficult for users to understand how to modify them after the fact. 
Recognising the importance of users' input to guide the solution, vendors of some of the 'high-end' scheduling software we evaluated allow the input of priority weights to optimisation criteria (e.g. tardiness, minimising setups). The transparency' of a system is known to influence the degree to which a human scheduler feels a sense of direct control, and is seen as a key design factor of scheduling decision support systems (Wiers 1997, 2001). Allowing users to input priority weights mily be thought to provide some sense of control without transparency. But as the way in which these weights are applied is opaque (sometimes to the employees of the software company), such adjustments have little more value than the psychological comfort of 'doing something' to try to guide the expensive software to a less naive solution: and that psychological comfort may be quickly lost if the new schedules the software proposes are nol in fact better.

Xilinx considered its scheduling system to be a potential source of competitive advantage, and hence the make-or-buy decision needed to reflect strategic ats well als tactical implications. Firms such as Wal*mart (cross-docking), Fed-Ex (in-transit visibility) and SCNF (scheduling; Ben-Khedher et al. 1998) have demonstrated how software can be used to support strategic business process capabilities. An off-the-shelf scheduling solution, available to any competitor might not put Xilinx at a competitive disadvantage, but would forego an opportunity to create a proprictary competitive advantage through improved scheduling.

In a survey of several manufacturing organisations facing make-or-buy decisions. Buchowicz (1991) found that firms which couched the make-or-buy decision in strategic, competitive terms tended to develop in-house, while firms that purchated off-the-shelf software tended to be dominated by professional values, and to be more concerned with peer approval and the need to have a "pseudo-rational justification. While there are undoubtedly circumstances where the competitive advintages that might be obtained from in-house development are outweighed by the potential cost savings of an off-the-shelf acquisition, we do not believe that those competitive advantages should be ignored.

Xilinx was concerned about the unstable environment in which a scheduling system would have to operate. Frequent product innovations, process and machine innovations, and changing customer priorities might each result in a need for changes to software logic. In such an environment code availability might be very important to the timeliness of modifications. Moreover, as timeliness of production is an important competitive consideration, a scheduling tool that heavily affects whether orders are on time is a competitive tool.

The scheduling system design/support team must also be available and flexible for fast modifications. It has been our experience that design team availability to the users, as well as openness to criticism and modifications, help determine the system 's usefulness. The relationship between the design team and the users, as well at management support of the design efforts, may practically make-or-break the success of the design and implementation process.

At Xilinx, employee turnover was low, while in the software houses and associated consultancies we were evaluating, turnover appeared to be (as is perhaps typical for that industry) quite high. It was anticipated that important process knowledge would be garnered during the development and implementation of the scheduling system. And while there is no guarantee that the individuals acquiring such knowledge might remain accessible (either with Xilinx, or a software vendor) 
the relative base rates (that is, relative turnover between Xilinx and the software vendors) were a source of concern and a decision factor.

Thus, we felt that on the criteria of operational efficiency and effectiveness, in terms of timeliness of modifications and control of the logic and algorithms, an in-house development was superior. While integration with some future off-the-shelf enterprise system was a concern, at that time Xilinx was also pursuing an 'open architecture' data-bus solution for enterprise system inter-operability, and we felt that a scheduling system developed in-house would be just as easily integrated into that architecture as an off-the-shelf system.

\section{Organisational learning}

Although it may seem that the trend in software is heavily toward outsourcing and inter-organisational relationships to foster learning (Holmqvist 2004), and that an acquisition of outside experience in the form of software might foster better learning outcomes, the reality of organisational learning is more complex. It may also seem that internal projects would be an exploitation of resources, while external acquisitions would be an exploration of new potential. However, the reality appears to be that the two kinds of learning (organisational and inter-organisational) are interwoven, and that exploratory learning happens with internal projects as well (Holmqvist 2004). Much of the experience in scheduling software is coded into algorithms, which vendors often claim as proprietary information. While there is undoubtedly learning to be gained by the elaboration of business processes needed to implement a scheduling software package, much of that learning may occur whether an organisation is :implementing off-the-shelf or in-house software. Some of the business process learning in an off-the-shelf implementation flows from the customer to the vendor. Of course, the argument can be made (by software vendors) that they have exposure to a broad range of firms in roughly the same line of business, and that they can bring knowledge of 'best practice' to their clients. While we have no data to argue this point either way, we would like to point out that the fact that a software firm "may have acquired knowledge of best practice of the industry from 'other firms' tends to support our point that the knowledge transfer can be in the other direction.

Hence, some firms maintain an in-house capability for software development at least in part because of considerations of organisational learning. Chrysler, for example, considers : software projects an essential part of its 'knowledge factory' (Landes et al. 1999); and while organisational learning is only one part of good knowledge management, it is a necessary part.

The kinds of learning that can take place in such development projects have been categorised as either model-building, or model-maintenance learning (Zhong and Majchrzak 2004). Model-building learning is clearly the more important, as it involves adapting to new knowledge, and building new conceptual structures that are important in generating further process innovations out of a development project. Some amount of model-building learning can take place in the customisation of an off-the-shelf system. However, the kind of in-depth discussion or cognitive elaboration (Zhong and Majchrzak 2004) of algorithms and processes needed to foster model-building knowledge from an off-thc-shelf implementation is far less 
likely to occur. Software vendors, as already noted, are reluctant to share the details of algorithms, and indeed their representatives working with the clients may themselves lack a deep understanding of those algorithms. In addition the vendors incentive in implementing their system is not to garner an in-depth understinding of the client's processes (which might require a useful cognitive elaboration from the customer) but simply to satisfy the customer that the system "works" as quickly and cheaply as possible.

The pool of industrial enginecring and process expertise at Xilinx wals also an important factor when considering the relative impact on organisational learning. Learning is the acquisition of knowledge; and knowledge, like wealth. may best accrue to those that already have an existing fund and facility to make use of it. There is evidence that firms with extensive existing knowledge in the problem doman more readily undertake software process innovations within that domain. and the kearning that result from them (Fichman and Kemerer 1997).

Finally, as we will discuss in more detail in the next section on cost. many off-theshelf packages contain implicit assumptions about business processes that are different from the ones a company currently follows, and hence have information requirements and outputs that do not at first appear to be within the limited scope of the system requirements that first prompted a firm to seck a software solution. In the case of enterprise resource planning software, it is common to hear that a firm must adapt its business practices to suit those of the software (Austin et al. 1999). This is often defended as a benefit, because "best practices" business process assumptions are imbedded in the software. Hence, modifying the firm's business proceses is seen as a form of organisational learning. Ironically, however, studies of software lirms indicate that they themselves are reluctant to adopt software that requires a process innovation, at least in part because of the recognition that existing business processes reflect strategic, competitive priorities and that a change in those processes maly necessitate a change in competitive strategy (Rifkin 2001).

In sum, we decided that one of the most important benefits of an in-house development at Xilinx would be the expert knowledge that would be spread among the design team members, as well as the user group. We hoped that this expertise would later benefit the company by being incorporated into process improvement initiatives and development of other computerised systems, since the design team members were company employees. In retrospect, this proved to be the case. as all but one of the employees involved with this effort were still cmployed by Xilinx five years after it started, and they had used the knowledge gained in the implementation described in this article to generate other systems, including a capacity analysis system.

\section{Cost}

We note at the outset of our cost comparison that the off-the-shelf systems we were evaluating all had many capabilities in excess of Xilinx' requirements. that Xilinx than the development cost of a system tailored to Xilinx' requirements, and thit we might seck to somehow value that extra functionality, against the possibility that Xilinx' shop floor might 'grow into' the requirement. However. as Thelen and 
Morrison (1993) pointed out, these additional features also add cost. Those authors cvaluated nine off-the-shelf software packages for job-shop scheduling, and found that none were as good as an in-house system, primarily because of the superflous features offered, and the cost of gathering and maintaining the supcrfluous information needed to run them.

Cost comparison of vendor versus in-house development of a scheduling system can be divided into the three phases of the project, namely design, implementation and maintenance.

The design of a scheduling system requires industrial enginecring/operations research (IE/OR, hereafter) expertise, programming expertise, and process expertise. Process expertise can typically be found in the form of one or more senior/long-term company employees. The time and dedication (and, therefore, cost) of these employees are necessary in the design and implementation phases, regardless of whether the system is developed in-house or acquired off-the-shelf (and customised). While in our evaluations, the estimated time required from process experts varied considerably depending on the vendor, the time estimates were not significantly lower for off-the-shelf implementations, and indeed were sometimes higher. But it is important to note that the tradeoff here is between time spent sharing knowledge with another employee (and hence distributing corporate knowledge within the organisation) and time spent sharing knowledge outside the organisation. (Of course, when a firm lacks state-of-the-art process expertise, knowledge may transfer from the vendor to the process experts as well, but at least in the case of Xilinx and the vendors in question, the process knowledge transfer from the vendor to the company was deemed to be negligible.) The cost of IE/OR and programming expertise is substantial in both cases. A company must compare the cost of acquiring the expertise in the form of employing the necessary personnel, to the cost of purchasing the expertise from a vendor. Of course, in some firms, the relative scarcity of the labour in question (programming and/or process expertise) might drive the decision to outsource, beyond a simple labour cost calculation.

For the devclopment of our in-house system, the project leader had a doctorate in industrial enginecring and programming expertise. Another industrial engineer with similar background was added, and the process expert who completed the team had programming expertise as well. We felt that a significant amount of time would be required from this team whether the development was in-house, or off-the-shelf. While certainly some design time would be eliminated by using an off-the-shelf system, our sense was that the time required to get our team at Xilinx fully up to speed on the off-the-shelf designs would be approximately the same (depending on the vendor) as the time required to gather specifications for an in-house development, since our team at Xilinx already had a great deal of familiarity with the process. In our cost comparisons (see table 2) we thus only included the incremental time that would be required to actually program the in-house system.

The availability of process expertise is crucial for implementation and maintenance in such projects. In this case the process was best known to the production manager, who had been providing the schedules to the test-floor he was in charge of for several years. This expert's co-operation was invaluable, and his dedication was a necessary condition to designing the system in-house. We felt that the amount of his time that would be required for implementation would probably 
Table 2. Cost comparison, 2005 dollars.

Average off-the-shelf

In-house

(low, average, high)

Development stage

$\$ 64200$

$(\$ 205000, \$ 321200, \$+00600)$

Implementation

$\$ 72300$

$(\$ 145000 . \$ 240900 . \$ 325600)$

Maintenance

Annual

$\$ 16100$

PV (5 years, $10 \%)$

$\$ 61000$

Lifecycle cost

S197500

$(\$ 14000.548200, \$ 6.5000)$

$\$ 1 \$ 2700$

$\$ 744800$

be less with an in-house development, as the development team would at least be up to speed on the basics of the production process, and much of the production terminology used by Xilinx. To be conservative, however, we did not include the additional cost of the production manager's time in the implementation of the offthe-shelf system. The implementation cost for the off-the shelf systems represents an average estimate from vendors and related consulting groups. The in-house implementation cost was calculated from the fully-burdened salary of the other two team members (not the production manager) and an estimalc of the lime required to train users.

The maintenance costs of the system, as a percentage of the acquisition cost seemed very attractive from the off-the-shelf vendors, but we did not think that percentage represented a fair estimate of Xilinx maintenance costs. The flat percentage ignored the time organic personncl would need to understand the maintenance issue, codify it, and find a work around until the system could be fixed or enhanced. Moreover, while some of the software vendor's maintenance labour might be spread across multiple customers (and hence be less than the labour required for an in-house development), most of that was only programming lime. As all but one of the vendors we spoke to secmed to have relatively small customer bascs (even software firms with relatively high visibility had fewer than a dozen working implementations), we were also unsure of the degree to which their economies of scale woukd outweigh the markup they would necessarily expect to receive on their programmers' time. We felt that the fixed-percentage maintenance contract merely obscured these underlying economics, as in the short run the software vendor would have the option of lowering their service costs in some way (delayed or degraded service) if maintenance expectations outstripped the nominal fee. In the end, we decided that most of the organic cost required for maintenance (analysis and workaround) would be similar regardless of where the software was developed, and included only the time we thought represented a reasonable level of programming support and analysis for an in-house solution.

Five software vendors were evaluated for potential solution quality, company reliability and expertise. What is shown in table 2 is an average, high and low of those costs. While some vendors had lower costs, the average is a good indication of the tradeoff between in-house development and off-the-shelf acquisition. 
Finally, we recognised that our in-house estimates for development and maintenance were more subjective, and more variable than the price quotes offered by vendors. We also realised that implementation expense, whether off-the-shelf or in-house, might vary substantially from the estimates. In such circumstances, a risk analysis, using Monte-Carlo simulation to gauge the probability that in-house costs might exceed off-the-shelf costs can be useful. However, given the magnitude of the cost differences between the alternatives, and the fact that in-house development seemed superior on all of the qualitative factors, we did not feel that a risk analysis was necessary.

In the end, it was cstimated that a decision-support system (DSS) tailored to Xilinx' specific application would be simpler, faster, more effective and less expensive than a generic, solution-providing system supplied by a vendor.

As noted above, one day per week was budgeted for ongoing support of this system, and that proved sufficient (as judged by lack of user complaints about response to support requests). While someone had to wear a beeper to be on-call for support, coverage across shifts also appeared to be adequate (again, based on lack of complaints). Detailed data were not kept on maintenance costs, but the initial estimate was used to derive the budgeted time for maintenance, and that budget was not changed in four years after the implementation of the system.

\section{Technical description of the system developed in-house}

The system developed in-house was called The Dispatcher. It was designed to be a user-friendly DSS, not a solution-providing, closed-loop (i.e. non-interactive) scheduling system.

The main requirements from the system were as follows:

- Determine and display lot processing requirements and urgency.

- Provide an efficient way to assign lots to resources and to sequence them for each resource.

- Provide an efficient way to re-schedule in the event of machinc breakdown.

- Provide sorting mechanisms for various performance measures.

- Provide and maintain process modeling accuracy and data accuracy.

- Provide data to user rapidly (run in less than five minutes).

The Dispatcher is an Excel-VBA-based decision support system. The main advantages of using Excel are the familiarity of most users with it, and the ease of data manipulation. It is meant to be used in an interactive fashion, displaying data inputs to a decision in an effective way, and giving prompt feedback about the quality of proposed decisions. The human decision maker remains a central part of implementation, but the need for expert scheduler knowledge is reduced, as some of the expert knowledge is built into the system (McKay and Wiers 2004).

Using macros, cell calculations, and Visual Basic code, The Dispatcher takes the current WIP data, and sorts it based on due-date and processing requirements. The system generates a separate priority list for each of the five main test-floor processing steps, namely Test, Mark, Bake, Scan, and Visual Inspection. The scheduler then makes the assignment (to one of several similar or identical resources) and sequencing decisions. Next, the scheduler provides the production manager with 
the schedule for each resource. Feedback from the manager may result in schedule modification. The final schedule is then provided to the operators and to the visual inspectors on paper and on their computer workstations. Rescheduling cin be performed off-line by the scheduler or the manager, and the new schedule is then provided to the operators.

The Dispatcher starts by downloading the current WIP datia file and deleting all the unnecessary information. Since the device identification number (DIN) contains most of the information pertaining to the lot processing requirements, the DIN is then parsed to its components. Based on the DIN and other lot attributes, the lots are sorted. Some lots are sent to the "Non-Dispatched" page. These lots may halve quality problems, require special processing, or should be kept in inventory until a customer order dictates their processing characteristics (see Brown "' al. 2000)). Most lots are sent to the 'Main' page to be dispatched.

In the 'Main' page the attributes of each lot are used to determine the remaining processing steps required. A look-up table is used to determine the preferred equipment type for the lot at each process step, and consequently the estimated processing duration of the lot. Lot changeover time is then calculated, ats well as the lot's critical ratio (CR), as follows:

$$
\mathrm{CR}=\frac{(\text { Due date }- \text { Present time) }}{\text { Remaining processing time }} .
$$

Based on the CR, lots are placed in one of five critical ratio groups (CRGs):

CRG1 for lots with $\mathrm{CR}<0$ (already tardy);

CRG2 for lots with $0=<\mathrm{CR}<1$ (will become tardy);

CRG3 for lots with $1=<\mathrm{CR}<2$ (if not immediately processed will become tardy): CRG4 for lots with $2=<\mathrm{CR}<4$ (medium urgency); CRG5 for lots with $4=<\mathrm{CR}$ (non-urgent).

Lots whose $\mathrm{CR}<2$ are cither tardy, or require urgent processing. These lots are thus highlighted, to signify that they require special attention. Although urgent these lots are already late, and actually hurts the OTD performance measure (since perceived necessary for gend processing them delays processing of other lots) it is

When a new lot requires customer satisfaction and goodwill.

its earliest arrival time to each step (no-wait). Fing steps, The Dispatcher estimates The Dispatcher provides estimated time (no-wait). For lots at upstream operations, by summing up the expected changeover and (ETA) to downstream operations, downstream operations. Although these and processing times prior to the practice allows the operators to setup ETAs may not be accurate, this urgent lots. The Dispatcher also performs static capacity calculations. The total capacity
requirements are summed for each CRG on each type of resource. The scheduler can
easily compare the capacity requirements management if action must be requirements to the availability, and report to 
As an Excel program, The Dispatcher accomodates various sorting algorithms. Therefore, switching the system from sorting based on one performance measures to another is simple:

During the development of The Dispatcher much emphasis was placed on the accuracy of process modeling. Clearly, the system designers wished to create a model of the test-floor that would perfectly imitate the real test-floor. Needless to say, mainly due to incompleteness of information and instability of the test-floor and its operating procedures, designing a complete model capturing every nuance that affects scheduling decisions is an impossible task. The trade-off between model accuracy and programming effort was considered numerous times during the design, and inclusion/exclusion decisions were made frequently. For example, lots of devices that require rework are rare, and cannot be easily distinguished from lots of new devices. The programming effort required to obtain the information needed for this distinction from the manufacturing exccution system database was substantial. Rework processing time is typically slightly shorter than the processing time of a new lot. Therefore, it was decided that the slight difference in duration and the rarity of rework lots did not justify the extra programming effort.

It was relatively simple to guarantee the accuracy of the data retrieved from the manufacturing execution system database. It was more complicated to maintain the accuracy of data in the internal lookup tables. Enginecring developments frequently result in new devices, as well as reduction of processing and changeover times. Modifications of The Dispatcher lookup tables must be coded with every such change. Therefore, procedures that guaranteed transfer of such information from the engineering department to the manufacturing department were put in place. To insure update, the maintainer of the dispatcher was added to the signature list for approved design changes. This table modification is done within the budgeted one day per week of maintenance.

The simplicity of The Dispatcher keeps its run time shorter than five minutes. The scheduler typically prepares a daily schedule in about an hour. Rescheduling is typically performed once or twice daily, and would typically be completed in 30 minutes (including the time to enter information about, e.g. machine breakdowns, etc.).

\section{Conclusions}

The Dispatcher was still in use four years after its implementation. By then, several vendor products evaluated as an alternative to The Dispatcher were no longer available. A schedule for the test-floor was created daily using the system, production supervisers used the system to reschedule in the event of machine breakdown, and test-floor operators used The Dispatcher routinely to obtain information pertaining to their schedule and to the urgency of the operations for which they were responsible. The performance improvements due to The Dispatcher are summarised in table 3.

The Dispatcher was only a small-scale success story at Xilinx. Small-scale, because it required a relatively small capital investment, and its contribution was limited to improving the San-Jose test-floor performance. Xilinx subcontracts 
Table 3. Performance improvement due to new scheduling system.

Direct and tangible

Organisational

On-time-delivery incrcased from $70 \%$ to $90 \%$

Lot lead time reduced by $30 \%$

Understanding of capacity issues led 10 development of better capacity planning system

Betler relationships and communication among operations, planning, and shop-floor

Acquired process knowledge led to several process improvement initiatives

Easier, more effective management of the production floor

the majority of its testing to vendors who use their own scheduling methods. The obvious contribution of The Dispatcher was, therefore, local. On-time delivery of the San-Jose facility increased from $70 \%$ to $90 \%$ on averalge, and lot lead-limes decreased by approximately $30 \%$. Time and skill requirements to create a daily schedule for the test-floor were reduced significantly, as detailed above.

Other contributions of The Dispatcher were perhaps more significant, although intangible. Through the use of The Dispatcher, the extent of the company's overloading policies and their consequences were better understood. The company was then able to use the process data collected for the design of The Dispalcher to develop a capacity analysis system of the entire company's manufacturing operations. In addition to the dissemination of process expertise described above better relationships were formed between various groups who relicd on better data to reach operational decisions. For example, disputes as to the cause of throughput problems could be discussed between the operations and planning group, referring to the hard data of what had been scheduled, and how the schedule had been modified. (Similar results may have been obtained with a vendor provided solution, we are merely pointing out that the result did not require a vendor provided solution.) Better relationships were also established between the system's developers and its users. These relationships later led to several successful process-improvement initiatives. In summary, the in-house development effort and the associated analysis, provided critical lcarning, knowledge and relationship-building for the re-engineering of the process.

This article, in addition to reporting on the contributions made by The Dispatcher at Xilinx, has also added to the literature on make-or-buy decisions for manufacturing software, by providing what we hope is a compelling example of a firm that has used in-house development as a core capability. Clearly each situation is unique in this regard, and we have already noted many of the unique factors at Xilinx that contributed to our decision to develop an in-house system. A complete list of these factors is presented in table 4. However, we think our framework and analysis of the problem may be useful for other corporations facing similar decisions, or researchers trying to build a more generic framework. Whilc some theoretical 
Table 4. Factors contributing to success of new scheduling system.

\begin{tabular}{|c|c|}
\hline Scheduling specific & Organisational \\
\hline $\begin{array}{l}\text { In-house availability of } \\
\text { scheduling expertise }\end{array}$ & $\begin{array}{l}\text { Atmosphere supporting in-house } \\
\text { developments }\end{array}$ \\
\hline $\begin{array}{l}\text { Availability of programming } \\
\text { expertise }\end{array}$ & $\begin{array}{l}\text { Open-architecture of information system } \\
\text { allowing integration of systems developed } \\
\text { in-house }\end{array}$ \\
\hline $\begin{array}{l}\text { Availability of process } \\
\text { expertise }\end{array}$ & $\begin{array}{l}\text { Low employee turnover leading to stability } \\
\text { of design and maintenance expertise } \\
\text { Good relationship between system design } \\
\text { team and system users } \\
\text { Top management support } \\
\text { Low on-time-delivery performance crisis: } \\
\text { reduces barriers to change } \\
\text { Perception of greater flexibility: that an } \\
\text { in-house system would be more } \\
\text { accommodating of modifications }\end{array}$ \\
\hline
\end{tabular}

work has appeared recently (e.g. Downing et al. 2003) there is clearly a great deal of work remaining. We think our paper helps in the development of a more general understanding of make-or-buy issues for manufacturing software.

\section{References}

Austin, R.D., Escalle, C.X. and Cotteleer, M., Enterprise Resource Planning, Technical Note 699020, 1999 (Harvard Business School Press).

Ben-Khedher, N., Kintanar, J., Qucille, C. and Stripling, W., Schedule optimisation at SNCF: From conception to day of departure. Interfaces, 1998, 28(1), 6-23.

Brown, A.O., Lee, H.L. and Petrakian, R., Xilinx improves its semiconductor supply chain using product and process postponement. Interfaces, 2000, 30(4), 65-80.

Buchowicz, B.S., A process model of make vs. buy decision making. The case of manufacturing software. IEEE Trans. Software Manage., 1991, 38(1), 24-32.

Carmon (Freed), T., Production planning and scheduling for semiconductor device testing. $\mathrm{PhD}$ disscrtation, Department of Industrial Engineering and Operations Research, University of California, Berkeley, C $\Lambda, 1995$.

Chen, T.R., Chang, :T.S., Chen, C.W. and Kao, J., Scheduling for IC sort and test with preemptiveness via Lagrangian relaxation. IEEE Trans. Syst. Man. Cyb., 1995, 25(8), $1249-1256$.

Chen, T.R. and Hsia, T.C., Scheduling for IC sort and test facilities with precedence constraints via Lagrangian relaxation. Manuf Syst., 1997, 16(2), 117.128.

Downing, C.E., Ficld, J.M. and Ritzman, L.P., The value of outsourcing: a field study. Inf. Syst. Manage., 2003, 20(1), 84-95.

Fichman, R.G. and Kemerer, C.F., The assimilation of software process innovations: an organisational learning perspective. Manage. Sci., 1997, 43(10), 1345-1363.

Freed (Carmon), T. and Leachman, R.C., A taxonomy of semiconductor device test scheduling problems. Working paper, Department of Industrial and Manufacturing Enginecring, California State Polytechnical University, 2001.

Glassy, C.R., Dynamic batching heuristic for simultaneous processing. IEEE Trans. Semicon. Manuf., 1991, 4(2), 77-82. 
Godin, V.B., Interactive scheduling: historical survey and state of the art. AIIE Trams.. 1978, 10(3), 331-337.

Hermann, J., Lee, C.-Y. and Hinchman, J., Global job shop scheduling with it genetic algorithm. Prod. Op. Manage., 1995, 4, 30-45.

Holmquist, M., Experiential learning processes of exploitation and exploration within and between organisations: an empirical study of produce development. Org. Sic. 2004. 15(1), 70-81.

LaForge, R.L. and Craighead, C.W., Computer-based scheduling in manulacturing lirms: some indicators of successful practice. Prod. Invent. Manage'. J.. 20000, I, 29) 34

Landes, D., Schneider, K. and IIoudek, F., Organisational learming and expericnte documentation in industrial software projects. Int. J. Ihumem-C'mmpuc\% Studic's, 1999, 51, 643-651.

Leachman, R.C. and Carmon (Freed), T., On capacity modeling for production planning with alternative machine types. IIE Trans. Sched. and Logist., 1942, 24(4), 6272.

Lee, C.-Y., Martin-Vega, L.A., Uzsoy, R. and I Inchman, J.. Implemmentalion of at decision support system for scheduling semiconductor test operations. I. Ifectrom. M/amb/.. 1993. 3, 121-131.

Lee, T.W., Using Qualitative Methods in Organisational Research. 1994) (Silge: Thousind Oaks. CA).

Lewin, K., Action research and minority problems. J. Sox. Issues. 1946. 2.34 t6.

McKay, K.N. and Wiers, V.C.S., Practical Production Control: A Survial civide Fon Planmers and Schedulers, 2004 (I. Ross: Ft. Lavderdale, FL).

McKay, K.N. and Wiers, V.C.S., Decision support for production scheduling tasks in thops with much uncertainty and little autonomous flexibility. In Homan Porommanc' in Planning and Scheduling, edited by B. MacCarthy and .1. Wilson. pp. 165 178. 2001 (Taylor and Francis: New York).

McKay, K.N., Safayeni, F.R. and Buzacott, J.A., Joh-shop scheduling theory: what is relevant? Interfaces, $1988, \mathbf{1 8}(4), 84-90$.

Ovacik, I.M. and Uzsoy, R., A shifting bottleneck algorithm for scheduling semiconductor testing operations. J. Electron. Manuf., 1992, 2, 119-134.

Ovacik, I.M. and Uzsoy, R., Rolling horizon algorithms for a single-machinc dynamic scheduling problem with sequence-dependent setup times. IIII. I. Prol. Ra.s. 1994. 32. $1243-1263$.

Ovacik, I.M. and Uzsoy, R., Rolling horizon procedures for dymamic parallel machine scheduling with sequence-dependent setup times. Int. J. Prol. Rex.. 1995. 33111\}. 3173-3192.

Ovacik, I.M. and Lzsoy, R., Docomposition methods for scheduling semiconductor testing facilities. Int. J. Flex. Manuf. Syst., 1996, 8, 357-388.

Saaty, T.L., Fundamentals of Decision Making and Priority. Theory with the Analvic Hirath! Process, 1994 (RWS Publications: Pittsburgh).

Schneewciss, I., Wetterauer, U., Semiconductor manufacturing. In Supply Cham Mamagmin and Advanced Planning, edited by H. Stadtler and C. Kilger, 3rd ed. pp. 421 43. 2005
(Springer: Berlin).

Stalk, G., Evans, P. and Shulman, L.E., Competing on capabilities: the new roles of corporate strategy. Har. Bus. Rev., 1992, 70(2), 57-69, March/April.

Thelen, R.A. and Morrison, K.R., Customised job shop scheduling application development. Comp. Indust. Eng.. 1993, 25(1-4), 215-128.

Uzsoy, R., Lec, C.-Y. and Martin-Vega, L.A., A review of production planning and performance models in the semiconductor industry. Part 1: System characteristics. 24(4), 47-61.

Uzsoy, R., Lee, C.-Y. and Martin-Vega, L.A., Scheduling semiconductor test operations: minimising maximum lateness and number of tardy jobs on a single machine. Naval Ri's
Logist., 1992b, 39, 369-388.

Uzsoy, R., Iee, C.-Y. and Martin-Vega, L.A., A review of production planning and scheduling models in the semiconductor industry. Part II: Shop floor control. IIF: Trm!s.
Sched. Logist., 1994, 26, 44-55. 
Uzsoy, R., Martin-Vega, L.A., Lee, C.-Y. and Leonard, P.A., Production scheduling algorithms for a semiconductor test facility. IEEE Trans. Semicon. Manuf,, 1991, 4, $270-280$.

Uzsoy, R., Martin-Vega, L.A., Lee, C.-Y. and Hinchman, J., Implementation of a decision support system for scheduling semiconductor test operations. Electron. Mantf., 1993, 3, $121-131$.

Wiers, V.C.S., Human-computer interaction in production scheduling: analysis and design of descision support systems for production scheduling tasks. PhD thesis, Findhoven University, 1997.

Wiers, V.C.S., Design of a knowledge-based scheduling system for a sheet material manufacturer. In Human Performance in Planning and Scheduting, edited by B. MacCarthy and J. Wilson, pp. 201-216, 200। (Taylor and Francis: New York).

Xiong, H.H. and Zhou, M.C., Scheduling of semiconductor test facility via Petri nets and hybrid heuristic search. IEEE Trans. Semicon. Manuf., 1998, 11(3), 384-393.

Zhong, J.Z. and Majchrzak, A., An exploration of impact of cognitive elaboration on learning in ISD Projects. Inform. Tech. Manage., 2004, 5(1-2), 143-159. 